\title{
Study of the growth and survival parameters of Macrobrachium rosenbergii shrimp depending on the type of feed used
}

\author{
Evgeny Tikhonov ${ }^{1, *}$, Valentin Bazykin ${ }^{2}$, Igor Grigorev $^{3}$, Sergey Solovyov ${ }^{4}$, and Elena \\ Radkevich ${ }^{4}$ \\ ${ }^{1}$ Petrozavodsk State University, 33, Lenina pr., 185910, Petrozavodsk, Russia \\ ${ }^{2}$ Federal Scientific Agroengineering Centre VIM, 3, Filtrovskoye sh., 196625, pos. Tyarlevo, Saint- \\ Petersburg, Russia \\ ${ }^{3}$ Arctic State Agrotechnological University, 3, Sergelyahskoe av., 677007, Yakutsk, Russia
}

\begin{abstract}
The aim of the study is to determine the effect of the feed type (Daphnia pulex-based feed and Dajana nano gran brand) on the water quality (presence of microorganisms and suspended solids) and on the growth and survival of Macrobrachium rosenbergii shrimp larvae. The study implementation plan involved 4 groups of shrimps placed under the same conditions, which were evaluated for 14 weeks through periodic observations and biometrics. The data obtained recorded significant differences between the groups where the best growth and survival results were obtained in organisms that received Dajana nano gran feed, regardless of water quality. In addition, the values of protein in shrimp meat up to $45 \%$ and different amounts of fatty acids were obtained. It was determined that the Daphnia pulex-based feed showed lower results in the growth rate and survival rate of Macrobrachium rosenbergii shrimp.
\end{abstract}

\section{Introduction}

Unplanned extraction of hydrobionts for human consumption has led to overexploitation of their natural sources, which increases annually due to human population growth [1]. However, the volume of catch of hydrobionts cannot increase endlessly [2]. In this situation, industrial aquaculture is an excellent alternative to intensive exploitation of biological water resources. At the moment, it is a sustainable industry that provides a significant part of the demand for fish and other seafood. To date, technologies for keeping trout both in open water and in closed water supply systems are quite well developed [3].

However, there are no scientifically based methods for growing giant Rosenberg shrimp. More or less developed methods exist for growing freshwater shrimp Litopenaeus vannamei [4]. At the same time, the giant Rosenberg shrimp is very promising from the point of view of commercial cultivation. Based on the existing experience of growing various types of shrimp, we can say that Macrobrachium rosenbergii is able to live in closed water supply systems with a high content of sediments and microorganisms, which

* Corresponding author: tihonov@psu.karelia.ru 
is important for its industrial cultivation. Macrobrachium rosenbergii is also known to have a very high protein content in its meat, which varies depending on the conditions of keeping and feeding [5].

Taking into account the above, it is necessary to conduct research aimed at developing methodological recommendations within the technology of growing this type of shrimp both for food purposes and for obtaining young shrimps for the purpose of preserving biodiversity in the relevant climatic zones [6]. The most important issue in industrial cultivation technology is the question of which type of feed provides the maximum nutritional needs necessary for this species to increase growth rates and nutritional value [7]. And the nutritional value of shrimp meat directly depends on the quality of the feed. The aim of this study is to comprehensively assess the 2 main parameters of industrial aquaculture: feed type and water quality, and their impact on the growth and survival of the Macrobrachium rosenbergii shrimp [8].

\section{Materials and methods}

The study was carried out on the basis of the Engineering Park of Petrozavodsk State University. The Engineering Park has a modular closed-loop water supply system, which allows you to keep enough shrimp for a statistically significant sample. According to the experiment plan, there are 2 input parameters: water quality and feed type and 2 output parameters: growth rate and survival rate [9]. Additionally, the nutritional content of the meat was evaluated. Water quality is a complex parameter and is determined by the amount of suspended solids combined with the number and type of microorganisms [10]. The studied water quality parameters are shown in Table 1.

Table 1. Water quality indicators for the maintenance of hydrobionts.

\begin{tabular}{|c|c|}
\hline Water quality indicators & Standard values \\
\hline Suspended particles, $\mathrm{mg} / \mathrm{l}$ & not more than 25 \\
\hline Total number of microorganisms, bill.cells/ml & not more than 3 \\
\hline
\end{tabular}

Water is considered of poor quality if the value of both parameters given in Table 1 is exceeded by $10 \%$. The developed plan of the experiment is presented in Table 2 .

Table 2. Plan of the experiment.

\begin{tabular}{|c|c|c|}
\hline No. of experiment & Feed type & Water quality \\
\hline $\mathrm{X} 1$ & Daphnia pulex & High \\
\hline $\mathrm{X} 2$ & Dajana nano gran & High \\
\hline $\mathrm{X} 3$ & Daphnia pulex & Low \\
\hline $\mathrm{X} 4$ & Dajana nano gran & Low \\
\hline
\end{tabular}

The experiments were performed with a 3 -fold repetition. The initial planting density was 30 pieces of giant Rosenberg shrimp larvae per 120 liters of water. The experimental tanks are made of propylene. At the initial stage of the experiments, the post-larvae had an average weight of $0.14 \mathrm{~g}( \pm 0.002 \mathrm{~g})$ and a length of $12.1 \mathrm{~mm}( \pm 0.7 \mathrm{~mm})$. Sections of plastic pipes were installed in the containers, which functioned as shelters during molting. The following water parameters were monitored daily: $\mathrm{pH}$, ammonium ions, oxygen, and temperature. The water used in experiments $\mathrm{X} 3$ and $\mathrm{X} 4$ was prepared in insulated containers. The obtained data were statistically processed, where the normality of the data distribution and compliance with the Bartlett criterion were checked. Then the analysis of variance was applied. In the survival data, the arithmetic mean and standard deviation were calculated. 
The study used 2 types of feed: Daphnia pulex-daphnia crustaceans up to $4 \mathrm{~mm}$ in size, and Dajana nano gran-a full-fledged shrimp feed. Feeding was carried out 2 times a day (in the morning and in the evening). The feeding rate was calculated at $4 \%$ of the biomass. Recalculation of the feeding rate was carried out weekly. The dry weight was determined using the principle of the constant mass method [11, 12]. During the experiment, daily monitoring of feed intake and removal of feed residues before the next feeding were carried out. The dry weight of the remaining feed was evaluated to determine the amount of feed consumed by the shrimp [13].

At the beginning and end of each experiment, a batch of 20 post-larvae and shrimp was used to determine live weight, dry weight, and organic dry weight. This data was used to evaluate the feeding efficiency based on the dry weight of the shrimp. The growth of postlarvae was estimated weekly by measuring all individuals. The distance from the cephalothorax to the Telson was measured using a caliper with an accuracy of $0.05 \mathrm{~mm}$ and a measurement range from 0 to $150 \mathrm{~mm}$. The live weight of the shrimps was determined using analytical scales with an accuracy of $0.001 \mathrm{~g}$. In addition, the specific growth rate (TEC) per week in length was determined using a modified formula [14], defined as follows:

$$
\mathrm{TECL}=\frac{\ln \left(\mathrm{L}_{\mathrm{e}}\right)-\ln \left(\mathrm{L}_{\mathrm{b}}\right)}{\mathrm{t}} \times 100,
$$

where $\mathrm{L}_{\mathrm{e}}$ - final length, $\mathrm{mm}, \mathrm{L}_{\mathrm{b}}$ - initial length, mm, $\mathrm{t}$ - time, $\mathrm{hr}$.

The intensity of mass gain was determined as follows:

$$
\mathrm{TECW}=\frac{\ln \left(\mathrm{W}_{\mathrm{e}}\right)-\ln \left(\mathrm{W}_{\mathrm{b}}\right)}{\mathrm{t}} \times 100,
$$

where $\mathrm{W}_{\mathrm{e}}$ - final weight, g. $\mathrm{W}_{\mathrm{b}}$ - initial weight, g. $\mathrm{t}-$ time, $\mathrm{hr}$.

Survival was calculated weekly using daily data on dead and living shrimps in experimental units, by dividing the final number of organisms per week by the initial number of organisms, and then multiplying by 100 .

The biochemical composition of the Dajana nano gran brand feed, according to the manufacturer's information, is as follows: proteins $35 \%$, lipids $8 \%$, carbohydrates $5 \%$, vitamins (A, D-3, E, K, thiamine, riboflavin, niacin, pantothenic acid, pyridoxine, B12, biotin, folic acid, choline chloride, ascorbic acid, inositol) and minerals ( $\mathrm{CaCO} 3$, $\mathrm{NaH} 2 \mathrm{PO} 4, \mathrm{Ca}(\mathrm{H} 2 \mathrm{PO} 4), \mathrm{NaCl}, \mathrm{MgSO} 4, \mathrm{FeSO} 4)-52 \%$. To evaluate the composition of the feed based on Daphnia pulex, the average values from various sources were considered: arginine $10.92 \%$, histidine $2.69 \%$, tyrosine $4.27 \%$, cystine $1.17 \%$, methionine $3.45 \%$, $\mathrm{Ca}=0.21 \mathrm{mg} / \mathrm{g}, \mathrm{Mg}=0.12 \mathrm{mg} / \mathrm{g}, \mathrm{P}=1.46 \mathrm{mg} / \mathrm{g}, \mathrm{K} 0.72 \mathrm{mg} / \mathrm{g}, \mathrm{Fe}=72.2 \mathrm{mg} / \mathrm{g}, \mathrm{Mn}=13.2 \mathrm{mg} / \mathrm{g}$, $\mathrm{Cu}=1.2 \mathrm{mg} / \mathrm{g}$.

\section{Results}

The measurement results showed a high stability of the physical and chemical parameters described in the previous section in all the experiments of the study (see Table 3).

Table 3. Average values of recorded water parameters.

\begin{tabular}{|l|c|c|}
\hline & High quality water (X1, X2) & Low quality water (X3, X4) \\
\hline Ammonium, mg/l & $0.00 \pm 0$ & $0.03 \pm 0.009$ \\
\hline Alkalinity, mg/l & $40-80$ & $45-80$ \\
\hline Oxygen, mg/l & $5 \pm 0.02$ & $5 \pm 0.04$ \\
\hline $\begin{array}{l}\text { Total number of } \\
\text { microorganisms, bill.cells/ml }\end{array}$ & 0 & 24 \\
\hline
\end{tabular}


As can be seen from the table, a high content of microorganisms is observed in experiments with low-quality water (X3 and X4). With regard to the consumption of different types of feed, it was noted that the shrimp consumed different amounts of feed from the calculated feeding rate. During the first 3 weeks, about $10 \%$ of the feed not consumed was recorded, and then this figure decreased to a value close to $3 \%$. Data on the growth of shrimps (length and live weight) showed significant differences between the experiments. At the same time, it was found that the type of feed has a significant impact on growth, regardless of the quality of the water used. The dynamics of weight gain when using Dajana nano gran brand feeds (experiments X2 and X4) and Daphnia pulex-based feeds (experiments X1 and X3) is shown in Figure 1.

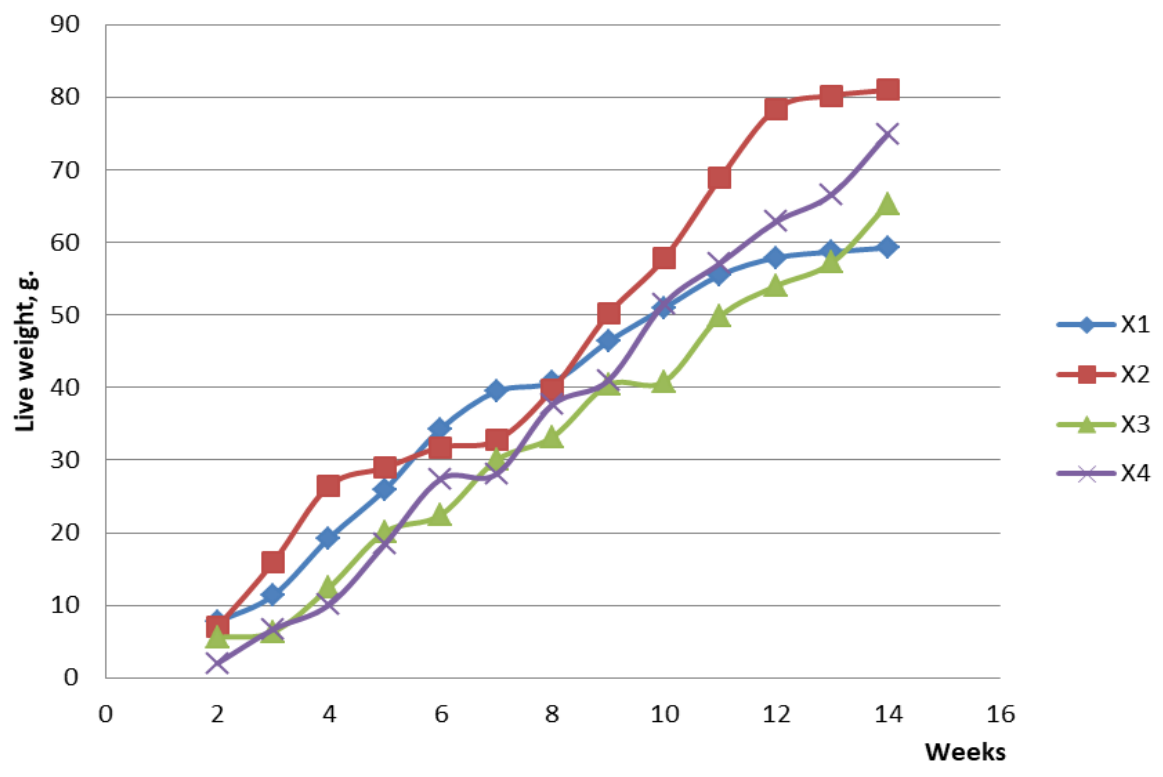

Fig. 1. Dynamics of the increase in live weight.

The increase in live weight shows a tendency to intermittent or abrupt growth, almost throughout the entire study period. The maximum average weight was $81 \mathrm{~g}$, in the X2 experiment. In the X4 experiment, high results were also obtained - $76 \mathrm{~g}$. At the same time, in experiments $\mathrm{X} 1$ and $\mathrm{X} 3$, the average weight of shrimps is significantly less and is $59 \mathrm{~g}$ and $64 \mathrm{~g}$, respectively. Similar results were obtained for increasing the length of shrimps (see Figure 2), which also show a tendency to jump growth. The maximum average length was $121 \mathrm{~mm}$ in the X2 experiment and $117 \mathrm{~mm}$ in the X4 experiment. Similarly, in experiments $\mathrm{X} 1$ and $\mathrm{X} 3$, the average length of shrimps is significantly less and is $95 \mathrm{~g}$ and $77 \mathrm{~g}$, respectively.

Analyses of the content of various substances showed the following. The maximum protein content in shrimps was recorded in experiments X2 and X4 (see Table 4). The reverse situation is with carbohydrates: in experiments $\mathrm{X} 1$ and $\mathrm{X} 3$, the content is maximum, of which from 0.08 to $0.09 \%$ is raw fiber. The analysis of the lipids content revealed a slight difference in the experiments $\mathrm{X} 1, \mathrm{X} 3$ and $\mathrm{X} 4$, while in the experiment $\mathrm{X} 2$ the fat content is significantly higher.

When analyzing the content of various fatty acids, significant differences were recorded between the experiments (see Table 5). The highest values of the total amount of saturated fatty acids were recorded in the $\mathrm{X} 3$ experiment. As for other types of acids, the difference is insignificant. 


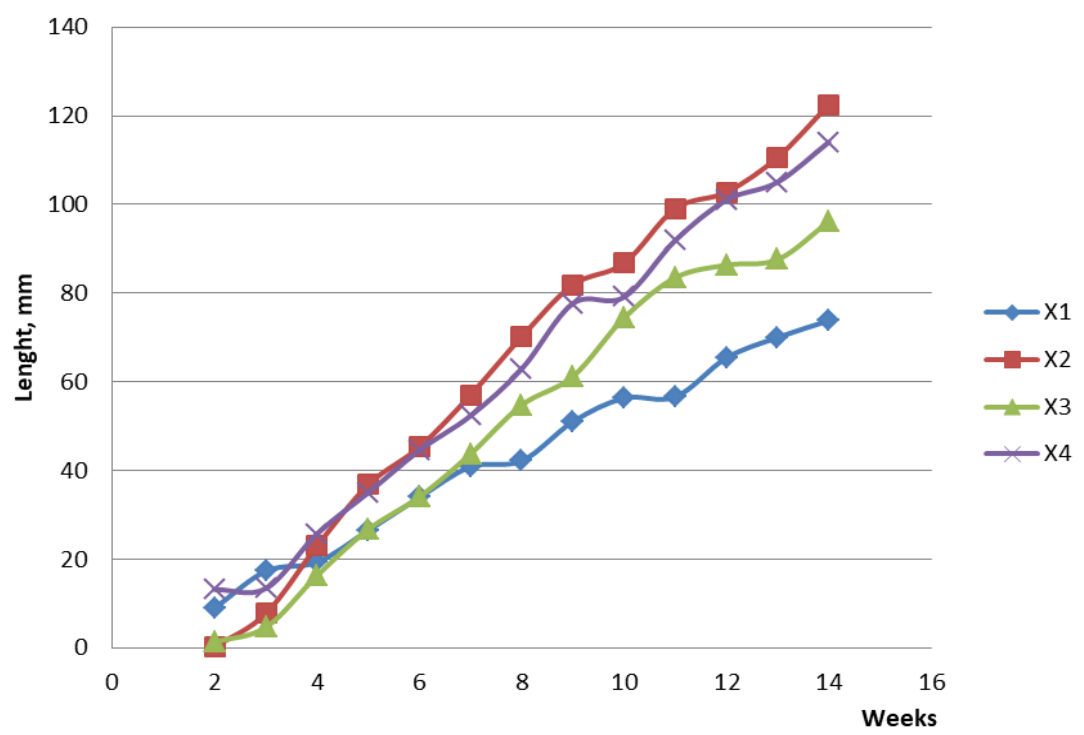

Fig. 2. Dynamics of length increase.

Table 4. The content of substances in shrimp meat.

\begin{tabular}{|l|c|c|c|c|}
\hline \multicolumn{1}{|c|}{ No. of experiment } & X1 & X2 & X3 & X4 \\
\hline Proteins, \% & $40 \pm 2.1$ & $47 \pm 1.8$ & $38 \pm 1.9$ & $46 \pm 1.4$ \\
\hline Carbohydrates, \% & $26 \pm 1.5$ & $16 \pm 0.7$ & $26 \pm 2.1$ & $17 \pm 1.8$ \\
\hline Lipids, \% & $4.8 \pm 0.2$ & $5.8 \pm 0.5$ & $4.2 \pm 0.6$ & $4.2 \pm 0.4$ \\
\hline
\end{tabular}

Table 5. Acids content.

\begin{tabular}{|l|c|c|c|c|}
\hline \multicolumn{1}{|c|}{ No. of Experiment } & X1 & X2 & X3 & X4 \\
\hline Saturated fatty acids, \% & $37.1 \pm 2.7$ & $42.7 \pm 0.6$ & $46.6 \pm 1.2$ & $41.5 \pm 1.1$ \\
\hline Monounsaturated fatty acids, \% & $31 \pm 1.5$ & $34.2 \pm 2.1$ & $32 \pm 1.3$ & $28.9 \pm 0.6$ \\
\hline Unsaturated fatty acids, \% & $31.9 \pm 2.0$ & $23.1 \pm 1.3$ & $21.4 \pm 1.8$ & $29.6 \pm 1.8$ \\
\hline
\end{tabular}

In total, 9 types of saturated fatty acids were registered, the amount of which varied depending on the type of acid. For monounsaturated fatty acids, 7 were identified. Finally, 6 unsaturated fatty acids were identified. The survival analysis showed significant differences between the experiments. The highest values were recorded in the experiments $\mathrm{X} 2(64 \%)$ and X4 (62\%). In contrast to X1 (46\%) and X3 (41\%). In general, there is a tendency to reduce mortality over time. At the same time, the maximum mortality was recorded at 5 and 6 weeks of the study: from 10 to $15 \%$ in X1 and X3 and from 5 to $10 \%$ in $\mathrm{X} 2$ and $\mathrm{X} 4$.

\section{Conclusion}

The growth of Macrobrachium rosenbergii shrimp is uneven. This is due to the molting process. Successful molting during the growth period is directly related to the quality of feed, as well as the conditions of maintenance [15]. Also, a common cause of death of shrimp is the situation with the inability to shed. This is primarily due to the balance of calcium in the body.

Studies have shown that the best growth and survival rates of Macrobrachium rosenbergii post-larvae are achieved when fed with balanced feeds, such as the Dajana nano 
gran brand, compared to Daphnia pulex-based feed. In this regard, the results obtained under controlled conditions allow us to establish that post-larvae weighing from $0.14 \mathrm{~g}$ of weight to $12.1 \mathrm{~mm}$ in length are easier to swallow a balanced feed, which allowed us to reach values of $81 \mathrm{~g}$ and $121 \mathrm{~mm}$ at the end of the study. Also, there are differences in the behavior of feed in the water column. Dajana nano gran brand feeds immediately fall to the bottom, which makes it easier to consume them by post-larvae. Daphnia pulex-based feeds remain on the surface and in the water column for a long time. This can be judged by observations made during the first 15 minutes after the addition of 2 types of feed and in the remaining feeds 12 hours after feeding.

The above-mentioned results confirm the fact that the quality of the feed is also directly related to the content of substances in the shrimp meat. It was determined that when feeding with balanced feeds, the protein content indicators are higher compared to the use of feeds based on Daphnia pulex. In addition, to fully understand the reasons for the high efficiency of a particular feed, it is necessary to perform a study aimed at identifying the types of amino acids, in order to determine the presence of essential amino acids and subsequently establish the real impact of these amino acids on the growth and development of Macrobrachium rosenbergii.

In addition, to fully understand the reasons for the high efficiency of a particular feed, it is necessary to perform a study aimed at identifying the types of amino acids, in order to determine the presence of essential amino acids and subsequently establish the real impact of these amino acids on the growth and development of Macrobrachium rosenbergii.

In terms of survival, the present study noted the effect of the feed type on the survival rate. The best results are observed in shrimps fed with a balanced feed like Dajana nano gran brand.

As for the physico-chemical parameters of the water recommended for the cultivation of Macrobrachium rosenbergii, the optimal temperature ranges between 27 and $29{ }^{\circ} \mathrm{C}$ were indicated. In this regard, the present study maintained a temperature of $28 \pm 1{ }^{\circ} \mathrm{C}$. The remaining physical and chemical parameters were monitored daily to maintain them in the required ranges: $\mathrm{pH}(7-8)$, alkalinity $(<80 \mathrm{mg} / 1)$, ammonium $(<1 \mathrm{mg} / \mathrm{L})$, and oxygen $(5$ $\mathrm{mg} / \mathrm{L})$.

\section{References}

1. F. Alshubiri, M. Elheddad, N. Doytch, Marine Policy 116, 103660 (2020) DOI: https://doi.org/10.1016/j.marpol.2019.103660

2. F.A. Bohnes, U.-P. Rodriguez, M. Nielsen et al., Food Policy 93, 101885 (2020) DOI: https://doi.org/10.1016/j.foodpol.2020.101885

3. J.T. Pulkkinen, T. Kiuru, S.L. Aalto et al., Aquacultural Engineering 82, 38-45 (2018) DOI: https://doi.org/10.1016/j.aquaeng.2018.06.003

4. L. de los Ríos-Pérez, G.R. Campos-Montes, A. Martínez-Ortega et al., Aquaculture 479, 442-446 (2017) DOI: https://doi.org/10.1016/j.aquaculture.2017.06.013

5. Pengfei Feng, Jinzhao He, Min Lv et al., Aquaculture 511, 734247 (2019) DOI: https://doi.org/10.1016/j.aquaculture. 2019.734247

6. Shaikh Mohammad Kais, Md Saidul Islam, Aquaculture 493, 406-415 (2018) https://doi.org/10.1016/j.aquaculture.2017.05.024

7. D.D. Kuhn, A.L. Lawrence, G.D. Boardman et al., Aquaculture 303(1-4), 28-33 (2010) DOI: https://doi.org/10.1016/j.aquaculture.2010.03.001 
8. Alokesh Kumar Ghosh, Joyanta Bir, Khandaker Anisul Huq, Aquaculture Reports 4, 112-117 (2016) https://doi.org/10.1016/j.aqrep.2016.08.001

9. Jie Wei, Lu Tian, Yakun Wang et al., Aquaculture 530, 735794 (2021) https://doi.org/10.1016/j.aquaculture.2020.735794

10. Md. Eilious Hosain, S. M. Nurul Amin, Mohd Salleh Kamarudin et al., Aquaculture 533, 736235 (2021) https://doi.org/10.1016/j.aquaculture.2020.736235

11. Zhijie Lu, Guang Yang, Zhendong Qin et al., Aquaculture 521, 735000 (2020) https://doi.org/10.1016/j.aquaculture.2020.735000

12. Yan Zhou, Na Guo, Zhenmeng Wang et al., Journal of Cleaner Production 294, 126135 (2021) https://doi.org/10.1016/j.jclepro.2021.126135

13. Bardera G, Owen M A G, Pountney D et al., Aquaculture 511, 734222 (2021) DOI: https://doi.org/10.1016/j.aquaculture.2019.734222

14. Xiaojian Gao, Yifan Zhou, Xinhai Zhu et al., Aquaculture 530, 735826 (2021) https://doi.org/10.1016/j.aquaculture.2020.735826

15. Hui Yang, Zhu Zhu, Haoran Xiong et al., Aquaculture 532, 736029 (2021) https://doi.org/10.1016/j.aquaculture.2020.736029 